\title{
Eye Care Industry Analysis
}

\author{
Akhilesh S. Pathipati, BA ${ }^{1}$ James C. Tsai, MD, MBA ${ }^{2}$ \\ ${ }^{1}$ Department of Ophthalmology, Stanford University School of \\ Medicine, Stanford, California \\ 2 Department of Ophthalmology, Icahn School of Medicine at Mount Sinai, \\ New York Eye and Ear Infirmary of Mount Sinai, New York, New York \\ Journal of Academic Ophthalmology 2018;10:e5-e11.
}

Address for correspondence James C. Tsai, MD, MBA, New York Eye and Ear Infirmary of Mount Sinai, 310 E. 14th Street, New York, NY 10003 (e-mail: Jtsai@nyee.edu).

\begin{abstract}
Keywords

- ophthalmology

- eye care

- industry analysis

- health care reform

Eye care is a large and growing industry in the United States. Demographic and lifestyle trends will spur increased demand in coming years, but industry earnings will depend on the state of regulation and health care reform. Ophthalmologists and optometrists are the two major service providers in the industry. While the markets for both professions are currently fragmented, the wave of consolidation and commoditization in health care will likely catch up to eye care in coming years. Scope of practice legislation continues to be a topic of heated debate. As it evolves, consolidated practices will move toward an integrated model that uses both types of providers to meet demand.
\end{abstract}

Eye care represents a more than $\$ 36$ billion industry in the United States ${ }^{1}$ (and over $\$ 70$ billion globally). ${ }^{2}$ Key players include health care service providers (ophthalmologists, optometrists, etc.), pharmaceutical companies, equipment/ goods manufacturers and retailers (glasses, lenses, medical devices, equipment, etc.), and the government. This analysis will focus on the perspective of service providers.

Broadly speaking, products and services in the industry cluster around two goals: refractive vision correction and treatment of eye diseases. There is strong demand for both types of services. Over 150 million Americans use corrective eyewear for refractive vision problems, ${ }^{3}$ with an estimated $\$ 21$ billion markets for glasses and contact lens sales. ${ }^{1}$ In addition, over 16 million Americans have had LASIK surgery to correct refractive error since 2000, accounting for another $\$ 2$ billion per year. ${ }^{4}$

While eye disease is less prevalent than refractive error, it is also common. ${ }^{3}$ More than 24 million Americans older than 40 years and half of Americans older than 75 years have cataracts. Nearly 10 million Americans have early age-related macular degeneration (AMD) while over 2 million suffer from late AMD, which can cause severe vision loss. Almost 8 million individuals have diabetic retinopathy (DR), and over 2.5 million have glaucoma. ${ }^{3}$ Industry analysts size the market for treatment of eye disease at over $\$ 15$ billion. $^{2}$

received

February 14, 2017

accepted after revision

December 5, 2017
DOI https://doi.org/

10.1055/s-0037-1620237. ISSN 2475-4757.

\section{Growing Demand}

The market for eye care is poised to grow due to both demographic and lifestyle trends. First and foremost, the United States has an aging population. The U.S. Census Bureau projects the number of people aged 65 and older to more than double by 2050 , to over 88 million ( - Fig. 1). ${ }^{5}$

Given that vision problems are more common as people age, demand for eye care is expected to correspondingly increase. For instance, there was a 20 to $25 \%$ increase in the number of individuals with cataracts, AMD, and glaucoma between 2000 and 2010 (-Fig. 2). ${ }^{6}$ The growth in all three of these age-related eye diseases will only accelerate as the population gets older.

Lifestyle trends support a greater need for eye care as well. Perhaps most significantly, there continues to be a pattern of poor nutrition and exercise in the United States. Diabetes has therefore become increasingly prevalent. Between 1995 and 2010, age-adjusted incidence of diabetes mellitus increased by $82.2 \% .{ }^{7} \mathrm{DR}$ is the most rapidly growing major eye disease, with an $89 \%$ increase in prevalence between 2000 and 2010 (-Fig. 2). ${ }^{6}$

Also with regard to lifestyle, Americans spend an increasing amount of time working on electronic devices. More than $90 \%$ of people spend over 2 hours per day looking at a screen,

Copyright $\odot 2018$ by Thieme Medical Publishers, Inc., 333 Seventh Avenue, New York, NY 10001, USA. Tel: +1(212) 584-4662.
License terms

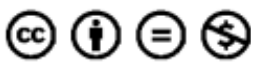




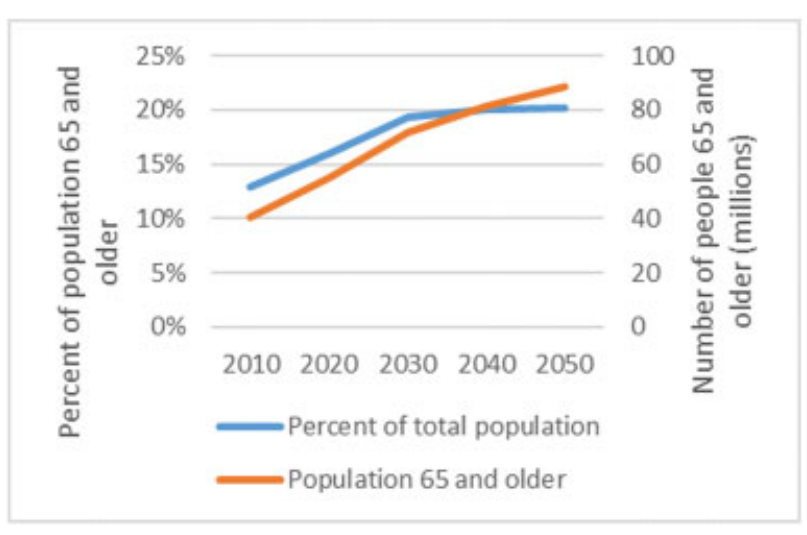

Fig. 1 Population age 65 and older.

with more than a quarter spending upward of 10 hours. This has led to a dramatic rise in "digital eye strain," with $65 \%$ of the population reporting symptoms such as dry or blurry eyes. ${ }^{8}$ While these symptoms are typically transient, they will likely lead to increased demand for eye care services by concerned patients.

Finally, refractive vision error is on the rise. Data from The Vision Council projects the population that needs corrective eyewear to exceed 217 million by $2020 .{ }^{9}$ Myopia in particular is becoming more common. ${ }^{10}$ The prevalence of nearsightedness in young adults in the United States has doubled in the past 50 years, which may be related to spending less time outdoors. Regardless of the cause, as myopia becomes more common, the need for refractive correction will grow, as will the incidence of myopia-related eye diseases.

Industry growth has been driven by eye diseases to a greater extent than refractive vision correction. Projections suggest spending on treatment of eye diseases will demonstrate greater than $4 \%$ annual growth, ${ }^{2}$ while correction of refractive error is projected to continue at approximately $2 \%$ each year. ${ }^{11}$

\section{Regulatory Environment's Effect on Potential Industry Earnings}

The trends described earlier will drive increased potential demand for eye care services. However, realized earnings depend on regulatory context, particularly with regard to insurance coverage and reimbursement.

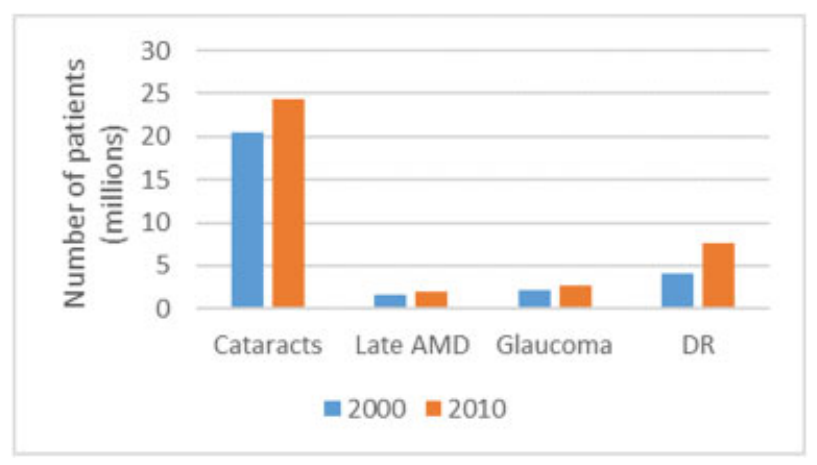

Fig. 2 Increase in disease prevalence 2000-2010.

\section{Insurance Coverage}

The Affordable Care Act increased the number of insured Americans by an estimated 20 million people since 2010. ${ }^{12}$ Although difficult to quantify, a greater number of insured patients have likely been one driver of demand for ophthalmology services over the past few years. The act also designated pediatric eye exams and coverage for corrective lenses as an Essential Health Benefit (EHB), increasing demand for refractive correction. ${ }^{13}$

However, the ACA affected ophthalmology less than other medical specialties. Given the correlation between eye problems and age, many ophthalmology patients are covered by Medicare rather than by private insurance. ${ }^{14}$ And while pediatric vision care was deemed an EHB, adult vision care (i.e., routine eye exams and glasses) was not.

The effect of the ACA may soon be a moot point. With the results of the last presidential election, health care is in a state of flux. President Trump has pledged to repeal the ACA, but it is unclear what will happen next.

The future of health care reform is of critical importance to health care providers. The current Administration promised not to implement policies that will cause individuals to lose coverage, ${ }^{15}$ but it remains to be seen how they will pursue their goals. The Congressional Budget Office found that early efforts to replace the ACA would cause over 20 million people to become uninsured. ${ }^{16}$ If such an effort ultimately passes, the eye care market will face a corresponding impact.

\section{Reimbursement}

The second aspect of health care reform that could affect the industry at large is reimbursement rates for treatment of eye diseases. Medicare rates are particularly important in ophthalmology given that eye problems often arise after age 65 years.

Health care spending currently accounts for approximately $18 \%$ of GDP, which makes U.S. health care by far the most expensive system in the world. ${ }^{17}$ Medicare represents $20 \%$ of that spending, with $\$ 646.2$ billion of expenditures in 2015.

This has created tremendous pressure on policymakers to reduce health care costs. These efforts fall under two broad approaches. The first has been an emphasis on "value-based care." Historically, health care providers were paid for their volume of services-a fee-for-service model. Under new models, reimbursements are tied to quality of care along with the quantity.

Medicare evaluates quality using an array of different metrics including outcomes, efficiency, and patient satisfaction. ${ }^{18}$ Additionally, "bundling" of payments ties reimbursements to an entire episode of care rather than individual services. For instance, the payment for a patient who had a heart attack would incorporate his or her hospitalization, follow-up appointments, and any readmissions instead of paying separately for each of those services.

If practices do not report quality data, they face a penalty on their Medicare reimbursements. Although tools for physician quality assessment remain flawed, the use of these measures has quickly made its way into practice. Between 2011 and 2015, Medicare payments through new models grew from 0 to $20 \%$ of reimbursements, ${ }^{19}$ and the Centers for Medicare and 
Medicaid Services (CMS) aim to tie $90 \%$ of reimbursements to "value" metrics by $2018 .^{20}$ To this end, Congress passed the Medicare Access and CHIP Reauthorization Act (MACRA) in 2015 with bipartisan support. MACRA expands the use of payments based on quality and efficiency. ${ }^{21,22}$

New payment models have had somewhat less effect on ophthalmology than other specialties. The initial goal of these efforts was to reduce costs associated with hospitalizations and emphasize care coordination around a primary care provider (PCP). Ophthalmology patients rarely require hospital stays and PCPs typically defer eye complaints to specialists. ${ }^{23}$

However, this is not to say that ophthalmology will be unaffected by new payment models. Most surgeries already receive global payments that encompass postoperative visits. There has also been increased interest in bundled payments for the management of chronic conditions, which could include chronic eye conditions like glaucoma and AMD. ${ }^{24,25}$ The growing emphasis on preventing disease rather than treating it will place downward pressure on spending in procedural fields like ophthalmology, potentially reducing industry earnings.

The second major approach to reducing health care costs has been to reduce reimbursement rates. This method has had a more direct impact on ophthalmologists. For example, Medicare reimbursement for cataract surgery has dropped more than $70 \%$ over the past 30 years. ${ }^{26}$ Granted, the reduction in reimbursement has been at least partially offset by an increase in efficiency. In this time span, ophthalmologists have transitioned from primarily performing conventional extracapsular cataract extraction to phacoemulsification, reducing the typical time required for cataract surgery from approximately 45 minutes to less than $20 .{ }^{27}$ Given that cataract surgeons can complete a surgery more quickly, the reimbursement reduction is not as large on a time-adjusted basis.

More recently, Medicare reimbursements have been cut for certain glaucoma and retina surgeries. CMS implemented reimbursement reductions of 25 to $30 \%$ for trabeculectomies and 16 to $34 \%$ for retinal detachment surgeries in 2016 to 2017, although these cuts were partially reversed after an intensive lobbying effort. ${ }^{28,29}$

Physician reimbursement will likely remain a target for spending cuts. With that said, the future of Medicare also remains the subject of political controversy. Paul Ryan and many congressional Republicans have advocated turning Medicare into a system of premium support (i.e., a voucher system). Under this model, the government would let Medicare beneficiaries use an allotted sum of money to select a plan on their own, including both public and private options. It is difficult to predict how reimbursements for eye care would fare under such a system.

\section{Service Providers}

There are two major types of service providers for eye care: ophthalmologists and optometrists. Ophthalmologists are medical doctors who complete medical school, an additional year of generalized medical or surgical training, and 3 years of specialty training on eye disease. They provide comprehensive eye care, including eye exams, refractive vision correction, medical diagnosis and treatment of disease, and surgical care. ${ }^{30}$ Ophthalmologists capture an estimated $\$ 12$ billion of the eye care market ( $33 \%$ of the market). ${ }^{1}$

Ophthalmologists typically work in one of three practice settings: private practice (either solo or in a group), academic health system, and nonacademic health system. Private practice currently predominates, with an estimated 75 to $80 \%$ of practitioners working for themselves rather than an employer. ${ }^{31,32}$ As a consequence of market fragmentation, competition between providers is medium to high, particularly in dense population centers. However, practice models may soon change (discussed in more detail later).

Optometrists are providers who complete 4 years of optometry school. Their primary role has traditionally been in refractive vision correction including eye exams and the prescription and sale of corrective eyewear. They have also begun to provide basic medical care and monitoring of eye disease. Optometrists are responsible for $85 \%$ of eye exams and $90 \%$ of refractive vision correction prescriptions in the United States and capture an estimated $\$ 15$ billion of the eye care market. Approximately 40\% comes from eye exams and $60 \%$ comes from the sale of glasses and contact lenses. ${ }^{9}$

Optometry is a highly fragmented industry as well. More than half of optometry practices have fewer than 5 employees, and the four largest providers account for less than $2 \%$ of revenue. $^{9}$

\section{Scope of Practice Battles}

Workforce issues are a major concern in ophthalmology. The Department of Health and Human Services projects a $1 \%$ decline in the supply of ophthalmologists to 17,350 between 2010 and 2020, yet they project a $19 \%$ increase in the need for ophthalmologists to 25,200 in that same time period, leaving a sizable shortage of ophthalmologists ( - Fig. 3). ${ }^{33}$ Despite growing demand, the number of ophthalmologists trained each year is limited by the availability of government funding. Several government agencies (primarily Medicare) provide funding for graduate medical education (GME) at teaching hospitals, thereby determining the physician supply (-Fig. 3). ${ }^{34}$

While the supply of ophthalmologists is limited by the government, the number of optometrists in the United States is expected to rise over the next 5 years. As of 2012, optometrists

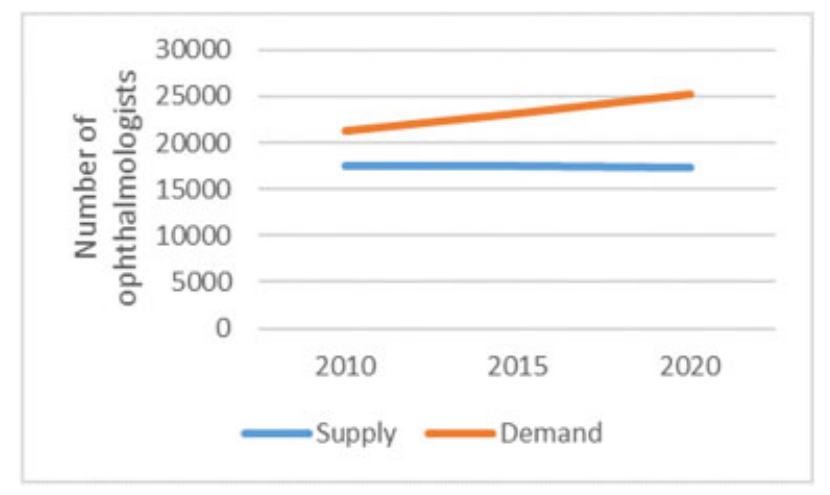

Fig. 3 Supply and demand of ophthalmologist. 
comprised $69 \%$ of eye care professionals, with that number expected to grow to $72 \%$ by $2020 .^{9}$

Scope of practice has therefore become a point of controversy in the industry. Optometrists have lobbied for increased responsibility in the diagnosis and treatment of eye disease to increase access to care. Dozens of bills have been proposed in state legislatures to give optometrists the ability to inject medicine into the eye, perform laser and scalpel procedures, and receive prescribing privileges to treat systemic illnesses that present with ocular pathology, including diabetes and hypertension. ${ }^{35}$

Ophthalmologists have vigorously opposed these efforts, citing substantial differences in education and training. Ophthalmologists complete 8 years of medical training, during which they must participate in a minimum of 364 surgeries as the primary surgeon or first assistant. ${ }^{35}$ By contrast, optometrists complete 4 years of optometry-specific school in which they do not receive medical or surgical training. Ophthalmologists argue that allowing them to perform surgery and prescribe drugs to treat systemic medical issues would threaten patient safety.

Patients' preferences skew heavily toward ophthalmologists when they are aware of the difference between the two professions. A National Consumer League survey found considerable confusion among patients about providers' credentials. Thirty percent of patients thought optometrists had medical degrees and nearly half thought optometrists had the credentials to be board certified in ophthalmology. When the difference between the two professions was clarified, over $90 \%$ of respondents preferred an ophthalmologist for both surgery and medication prescription. ${ }^{36}$

Most efforts to expand optometrist scope of practice have not passed. However, exceptions have made it through state legislatures with increasing frequency. In Oklahoma, legislative efforts in 1998 and 2004 gave optometrists the right to perform both laser and nonlaser (scalpel and injection) surgical procedures. Since 2014, optometrists have won scope of practice expansions in Louisiana, Arizona, Nebraska, Tennessee, and Kentucky that have increased their surgical scope and prescribing power. ${ }^{37,38}$

Scope of practice battles will undoubtedly continue in the future, but it is important to note that professional relationships between ophthalmologists and optometrists are often cordial and mutually beneficial. Many practices have moved toward an integrated delivery model in which ophthalmologists and optometrists work together (discussed in more detail later). ${ }^{39}$

\section{Trends in Practice Models}

\section{Consolidation of Practices}

American health care is in the midst of a transformation. Doctors are moving from a private practice model to one in which they are employed by hospitals. The proportion of independent physicians dropped from 57 to 39\% between 2000 and 2012. Meanwhile, the number of physician searches by hospitals grew by nearly $500 \%$ between 2004 and $2013 .{ }^{40}$ In essence, health care is becoming commoditized. Practices and hospitals are consolidating into large, integrated health systems.

To date, ophthalmologists have been less affected by these trends than other physicians. Only 20 to $25 \%$ of ophthalmologists are currently employed, compared with $60 \%$ of all doctors. $^{31,32}$ This may be because ophthalmologists do not generate as much revenue for hospitals as specialties who do more extensive testing and admitting.

According to data from a Merritt Hawkins revenue survey, an ophthalmologist generates just $\$ 842,711$ for a hospital, and claims $\$ 1$ of income for every $\$ 2.99$ of revenue. By contrast, an internal medicine physician generates an average of $\$ 1.7$ million for a hospital and claims $\$ 1$ of income for every $\$ 9.02$ of revenue. ${ }^{41}$ Hospitals therefore have a much smaller incentive to buy ophthalmology practices. - Fig. 4 summarizes revenue generated and revenue-to-compensation by specialty.

Even so, ophthalmologists will likely transition toward consolidated health systems in coming years for the same reasons that have made independent practice unsustainable in other specialties.

First, the regulatory burden of maintaining a practice has increased exponentially with new legislation. Administrative tasks related to the government and insurers place tremendous pressure on small private practices. Second, growth of electronic health records and meaningful use requirements have fundamentally reshaped how doctors interact with patients and have stretched the finances of many practices to a breaking point. Third, changes in payment systems emphasize the role of coordination and shared resources. This encourages movements away from the private practice system.

As a consequence, a generational shift is underway among doctors. Younger doctors are more likely to seek out salaried positions as employees rather than own a practice. Surveys

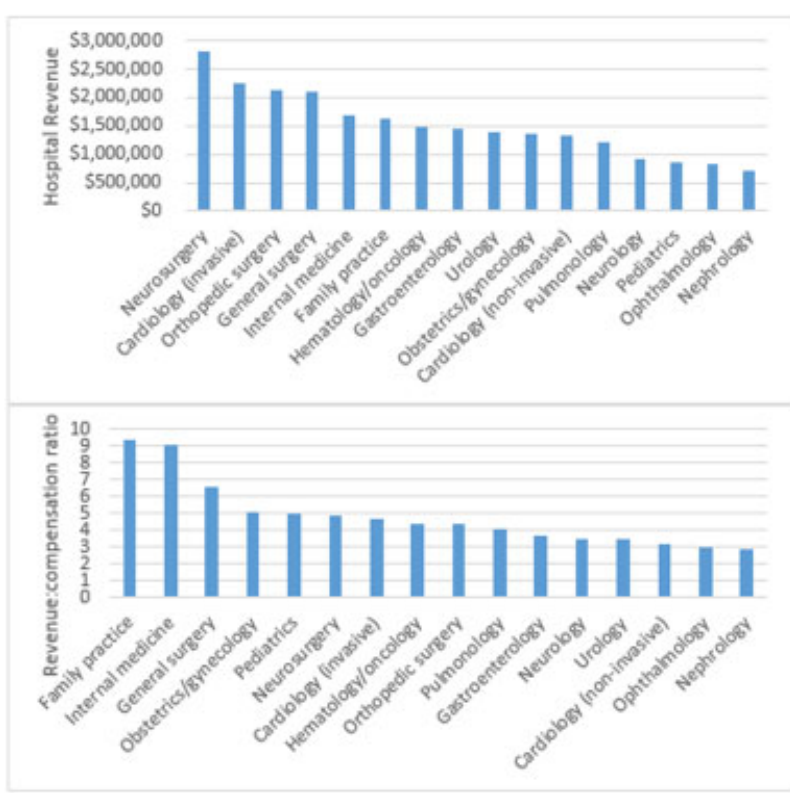

Fig. 4 Hospital revenue and revenue-to-compensation ratio by specialty. 
indicate that as many as $90 \%$ of medical students do not intend to go into private practice. ${ }^{42,43}$ The growing complexity of health care has led to considerably larger barriers to entry and many new doctors do not want to deal with the hassle of managing a business.

Hospital systems, on the other hand, have the scale to easily navigate these administrative hurdles, and as large entities, they have the bargaining power to negotiate better rates with payers and suppliers.

Hospitals may also find the purchase of ophthalmology practices more attractive moving forward because it is an avenue to add patients to an integrated health system. A patient who does not have a primary care physician may still independently seek out eye care. The hospital can then leverage this introduction to cover the rest of his or her health needs.

Optometrists have seen less consolidation than other health care providers, including ophthalmologists. Market concentration of optometrists actually decreased between 2011 and 2016, which industry analysts attribute to the financial rewards of opening solo practices in rural areas. ${ }^{9}$

The optometry market may soon start to consolidate as well, although the corporatization of optometry appears to be following a different pattern than physician markets. More specifically, national retail chains such as Lenscrafters and Costco are employing optometrists on a broad scale. ${ }^{11}$ Health systems and physician-led groups have also begun to hire optometrists, moving them from private practice to employment. $^{9}$

\section{Integrated Eye Care}

As discussed previously, there is a large unmet demand for ophthalmologic care that continues to grow over time. ${ }^{33}$ Current ophthalmology practices do not have the capacity to meet this demand. To improve efficiency, many practices (and health systems) are moving toward a model of "integrated eye care."

Integrated eye care incorporates both optometrists and ophthalmologists in a single practice. Estimates suggest that approximately one-third of a typical ophthalmologist's time is spent on routine eye care including exams and attending to basic medical needs. ${ }^{32,44}$ Integration compensates for the ophthalmologist shortage by leveraging the expansion of optometrists' scope of practice. Shifting routine responsibilities to optometrists frees ophthalmologists to focus on patients' more complicated problems and surgery.

Practices have already begun to adopt a dual-provider model in which optometrists handle primary eye care and ophthalmologists provide specialty coverage. A recent American Academy of Ophthalmology survey indicates that $50 \%$ of ophthalmologists now employ an optometrist, up from $28 \%$ in $1994 .{ }^{45}$ Integrated care will continue to evolve over time based on shifting attitudes between providers and scope of practice legislation.

\section{Movement Toward Subspecialization}

A related trend in the industry has been the shift of ophthalmologists from generalizing to specializing. Between 2003 and 2013 , there was a $20 \%$ drop in the number of general ophthalmologists and $41 \%$ increase in subspecialists. ${ }^{46}$

There are multiple drivers of subspecialization. With a decline in solo practices, there is a shrinking market for comprehensive ophthalmologists who perform many procedures. Larger groups that direct patients to a specialist for a given procedure may offer greater efficiency and more skilled providers. An ophthalmologist who does only cataracts is likely to be better at cataract surgery than one who handles cataracts, glaucoma, cornea, and more. In addition, the growing scope of optometrists has limited the need for ophthalmologists to provide routine eye care, a core function of many comprehensive ophthalmologists.

Granted, these trends are not universal. A rural ophthalmologist may continue to thrive as a comprehensive solo practitioner. However, the industry is undergoing dramatic changes and providers who are prepared for those changes will maximize value.

\section{Evolving Approach to Cataract Surgery}

A final trend in ophthalmology practices is the evolution of cataract surgery. Cataract surgery is among the most common ophthalmic procedures in the United States, with approximately 3.7 million surgeries performed each year. The vast majority are performed in outpatient centers such as Ambulatory Surgery Centers (ASCs), but there has been growing interest in office-based surgery.

Kaiser Permanente has been a leading proponent of this transition. Over $90 \%$ of cataract procedures at Kaiser Permanente Colorado since 2014 have been performed in an office setting. ${ }^{47}$ While many ophthalmologists have expressed concerns regarding patient safety in such cases, a retrospective study of more than 21,000 eyes found that cataract surgery performed in minor procedure rooms had efficacy and safety outcomes consistent with conventional methods. ${ }^{48}$ In addition, office-based surgery led to less preoperative testing and was performed without an anesthesiologist or nurse anesthetist.

A transition toward office-based cataract surgery will have profound implications for ophthalmologists. CMS is currently exploring reimbursement rates, which will likely be lower than the rate for surgeries performed in an ASC or hospital setting. In addition, surgeries performed in an office setting may not receive facility fees. ${ }^{47}$

Simultaneous, bilateral cataract surgery (SBCS) is also on the rise. Ophthalmologists have historically avoided operating on both eyes on the same day due to concerns regarding both safety and reimbursement. ${ }^{49}$ From a safety perspective, there is a fear of bilateral endophthalmitis, given that sameday procedures are not truly independent procedures, and high-risk patients may become blind if both eyes are infected after surgery. ${ }^{50}$ In addition, simultaneous surgery prevents surgeons from re-evaluating a patient's functional vision status after removing the first cataract. As a result, patients may receive unnecessary or less effective surgery on the second eye. From a financial standpoint, CMS reimburses the second eye at just $50 \%$ the rate of the first one, creating a strong incentive to do the surgeries separately. ${ }^{51}$ 
Despite ongoing concerns, a study of more than 4,700 Kaiser patients between 2009 and 2014 found that SBCS had minimal adverse events. It also increased efficiency and patient convenience by consolidating preoperative and postoperative appointments for the two eyes. ${ }^{52}$

Both office-based cataract surgery and same-day, bilateral surgery may therefore become more common going forward. Safety remains an important consideration, but Kaiser's success has demonstrated the viability of each model for uncomplicated cataracts.

At the same time, these changes may dramatically reduce the cost of cataract surgery. In an environment of increasingly integrated, cost-conscious care, cataracts represent a target for decreased spending. Payment systems may therefore change to create incentives to shift toward office-based, bilateral models.

\section{Conflict of Interest}

None declared.

\section{References}

1 Vision Industry Overview. Harris Williams \& Co.; 2015. Available at: http://www.harriswilliams.com/sites/default/files/content/hcls_vision_industry_overview.pdf

2 Kalorama Information. Advances in Ophthalmology: Markets in the Treatment of Eye Disorders and Corrective Vision. 2nd ed. 2009

3 American Academy of Ophthalmology. Eye Health Statistics. 2016. Available at: https://www.aao.org/newsroom/eye-healthstatistics\#. Accessed December 20, 2017

4 Statista. Number of Lasik Surgeries in the US from 1996-2020. 2016. Available at: https://www.statista.com/statistics/271478/ number-of-lasik-surgeries-in-the-us/.Accessed December 20, 2017

5 US Department of Health and Human Services, Administration of Community Living. Projected Future Growth of the Older Population. 2014. Available at: https://aoa.acl.gov/Aging_Statistics/ future_growth/future_growth.aspx. Accessed December 20, 2017

6 Prevent Blindness. New Vision Problems in the US. 2012. Available at: http://www.preventblindness.org/new-vision-problemsus-report. Accessed December 20, 2017

7 Centers for Disease Control and Prevention. Increasing Prevalence of Diagnosed Diabetes. 2012. Available at: https://www.cdc.gov/mmwr /preview/mmwrhtml/mm6145a4.htm. Accessed December 20, 2017

8 The Vision Council. Eyes Overexposed: The Digital Device Dilemma. 2016. Available at: https://visionimpactinstitute.org/research/eyesoverexposed-digital-device-dilemma/

9 Oliver K. Optometrists in the US. IBIS World Industry Reports; 2016

10 Dolgin E. The myopia boom. Nature 2015;519(7543):276-278

11 DeCarlo J. Eye Glasses and Contact Lens Stores in the US. IBIS World Industry Reports; 2016

12 US Department of Health and Human Services. 20 million people have gained health insurance coverage because of the Affordable Care Act. 2016. Available at: http://www.hhs.gov/about/news/ 2016/03/03/20-million-people-have-gained-health-insurancecoverage-because-affordable-care-act-new-estimates. Accessed December 20, 2017

13 Dang S, Gudgel D. The Affordable Care Act's Children's Eye Health Benefit. American Academy of Ophthalmology. 2014. Available at: https://www.aao.org/eye-health/news/affordable-care-acteye-benefit. Accessed December 20, 2017

14 Stuart A. The Affordable Care Act: A Look at its Impact on Ophthalmology. Eyenet; 2015
15 Jackson HC. 6 Promises Trump has made about health care. Politico. Available at: https://www.politico.com/story/2017/03/ trump-obamacare-promises-236021. Accessed March 17, 2017

16 Congressional Budget Office Cost Estimate. H.R. 1628, American Health Care Act of 2017. Congressional Budget Office; 2017. Available at: https://www.cbo.gov/publication/52752

17 National Health Expenditures 2015 Highlights. Centers for Medicare and Medicaid Services; 2016. Available at: https://www.cms. gov/Research-Statistics-Data-and-Systems/Statistics-Trends-andReports/NationalHealthExpendData/NationalHealthAccountsHistorical.html

18 Quality Measures. Centers for Medicare and Medicaid Services. Available at: https://www.cms.gov/Medicare/Quality-InitiativesPatient-Assessment-Instruments/QualityMeasures/index.html. Accessed January 2, 2018

19 Bendix J. From quantity to quality: Meeting the new demands of value-based care. Medical Economics. 2015. Available at: http:// medicaleconomics.modernmedicine.com/medical-economics/news /quantity-quality-meeting-new-demands-value-based-care?page=full. Accessed December 20, 2017

20 Van Dyke M. MACRA and the Giant Move into Value-based Payment. Hospital and Health Networks Magazine. 2016. Available at: http:// www.hhnmag.com/articles/7832-the-giant-move-into-value-basedpayment-via-macra. Accessed December 20, 2017

21 American Association of Family Physicians. MACRA Basics. 2016. Available at: http://www.aafp.org/practice-management/payment/ medicare-payment/faq.html\#macraimpact. Accessed December 20, 2017

22 American Academy of Ophthalmology. MACRA: Frequently Asked Questions. 2016. Available at: https://www.aao.org/advocacy/MACRAmedicare-access-chip-reauthorization-act/faqs. Accessed December 20, 2017

23 Chan TY, Rai AS, Lee E, Glicksman JT, Hutnik CM. Needs assessment of ophthalmology education for primary care physicians in training: comparison with the International Council of Ophthalmology recommendations. Clin Ophthalmol 2011;5:311-319

24 O'Byrne TJ, Shah ND, Wood D, et al. Episode-based payment: evaluating the impact on chronic conditions. Medicare Medicaid Res Rev 2013;3(03):. Doi: 10.5600/mmrr.003.03.a07

25 Meszaros L. Ophthalmologists to see new payment models, increased patient access. Ophthalmology Times. 2014. Available at: http://ophthalmologytimes.modernmedicine.com/ophthalmologytimes/content/tags/2014-glaucoma-360/ophthalmologists-see -new-payment-models-increased-?page=full. Accessed December 20,2017

26 Steinberg EP, Javitt JC, Sharkey PD, et al. The content and cost of cataract surgery. Arch Ophthalmol 1993;111(08):1041-1049

27 Maloney WF. The remarkable evolution of cataract surgery makes the last 20 years “a golden age." Ocular Surgery News. 2002. Available at: https://www.healio.com/ophthalmology/cataract-surgery/news/ print/ocular-surgery-news/\%7B9b5f0958-b3bf-49cd-a4c6-350b6edc dec3\%7D/the-remarkable-evolution-of-cataract-surgery-makes-thepast-20-years-a-golden-age. Accessed December 20, 2017

28 Harrison L. How Medicare Reimbursement Cuts Are Reshaping Ophthalmology. Medscape. 2015. Available at: http://www.medscape.com/viewarticle/856272. Accessed December 20, 2017

29 American Society of Cataract and Refractive Surgery. 2017 Medicare Physician Fee Schedule Proposed Rule Released. 2016. Available at: http://www.ascrs.org/about-ascrs/news-about/2017-medicarephysician-fee-schedule-proposed-rule-released-ascrs-and-ophtha Imic-community-advocacy. Accessed December 20, 2017

30 American Academy of Ophthalmology. Differences in Education Between Optometrists and Ophthalmologists. 2011. Available at: https://www.aao.org/about/policies/differences-education-opto metrists-ophthalmologists. Accessed December 20, 2017

31 Rosenthal E. Apprehensive, Many Doctors Shift to Jobs with Salaries. The New York Times. 2014. Available at: https://www. 
nytimes.com/2014/02/14/us/salaried-doctors-may-not-lead-tocheaper-health-care.html. Accessed December 20, 2017

32 Pinto J. Practice management: Facts, industry trends and performance benchmarks. Ocular Surgery News. 2008. Available at: http://www.healio.com/ophthalmology/practice-management/ news/online/\%7B95f91829-b0cd-46b2-9614-756f6773f8b5\%7D/ practice-management-facts-industry-trends-and-performancebenchmarks. Accessed December 20, 2017

33 US Department of Health and Human Services. Physician Supply and Demand: Projections to 2020. Available at: https://bhw.hrsa. gov/sites/default/files/bhw/nchwa/projections/physician2020projections.pdf. Accessed December 20, 2017

34 Eden J, Berwick D, Wilensky G. Graduate Medical Education That Meets the Nation's Health Needs. Washington, DC: National Academies Press; 2014

35 Schleiter KE. Ophthalmologists, optometrists, and scope of practice concerns. Virtual Mentor 2010;12(12):941-945

36 Wolkoff L. Survey finds public is confused about who performs eye care. Ocular Surgery News. 2006. Available at: https://www.healio. com/ophthalmology/news/print/ocular-surgery-news/\%7 B9c4a89a40abf-4357-a518-c622bc6b47c1\%7D/survey-finds-public-is-confusedabout-who-performs-eye-care. Accessed January 2, 2018

37 Lubell J. In Scope. AOA Focus. 2014. Available at: http://www.aoa. org/news/aoa-focus/novemberdecember-2014/in-scope?sso=y. Accessed December 20, 2017

38 Passut J.Kentucky governor signs law to expand optometric scope of practice. Eye World. March 2011. Available at: https://www.eyeworld.org/article-kentucky-governor-signs-law-to-expand-optometric-scope-of-practice

39 Boyle EL. Relationship between MDs, ODs changing as integrated eye care gains in popularity. Ocular Surgery News. 2009. Available at: https://www.healio.com/ophthalmology/practice-management/news/print/ocular-surgery-news/\%7B05f02ee9-f487483c-9acd-6eb1624f688a\%7D/relationship-between-mds-odschanging-as-integrated-eye-care-gains-in-popularity. Accessed December 20, 2017

40 Pathipati A. Doctor-patient relationships evolving with technology. The Sacramento Bee. 2015. Available at: http://www.sacbee.com/ opinion/op-ed/soapbox/article30777270.html. Accessed December 20, 2017

41 Herman B. Physician-Generated Hospital Revenue vs. Salary: 48 Statistics. Becker's Hospital Review. 2012. Available at: http:// www.beckershospitalreview.com/compensation-issues/physician-generated-hospital-revenue-vs-salary-48-statistics.html. Accessed December 20, 2017

42 Arvantes J. Newly Minted FPs Agree with Survey That Shows Growing Trend Toward Salaried Positions. American Association of Family Physicians. 2012. Available at: http://www.aafp.org/ news/education-professional-development/20120118employeddocs.html. Accessed December 20, 2017

43 Carroll M. Survey Shows 90\% of Future Physicians Intend to Avoid Private Practice. Advantage Healthcare Consulting. 2015. Available at: https://www.advadm.com/survey-shows-90-of-future-physiciansintend-to-avoid-private-practice/. Accessed December 20, 2017

44 Pinto J. Principles of optometrist compensation. Ocular Surgery News. 2010. Available at: http://www.healio.com/ophthalmology/practice-management/news/print/ocular-surgery-news/\% 7B8de80616-781f-44b9-bbab-4787e93189ce\%7D/principles-ofoptometrist-compensation. Accessed December 20, 2017

45 Bethke W. What's the future of private practice? Review of Ophthalmology. 2011. Available at: https://www.reviewofophthalmology. com/article/whats-the-future-of-private-practice. Accessed December 20, 2017

46 Kent C. Can a comprehensive practice still survive? Review of Ophthalmology. 2014. Available at: https://www.reviewofophthalmology.com/article/can-a-comprehensive-practice-still-survive. Accessed December 20, 2017

47 CMS assesses office-based cataract surgery. Ocular Surgery News. 2016. Available at: https://www.healio.com/ophthalmology/practice-management/news/print/ocular-surgery-news/\%7B04bf9725e0f6-42d7-bc18-b5345aaf3335\%7D/cms-assesses-office-basedcataract-surgery. Accessed January 2, 2018

48 Ianchulev T, Litoff D, Ellinger D, Stiverson K, Packer M. Officebased cataract surgery: population health outcomes study of more than 21,000 cases in the United States. Ophthalmology 2016;123(04):723-728

49 Same-day bilateral cataract surgery gains ground, but obstacles remain. Ocular Surgery News. 2015. Available at: http://www. healio.com/ophthalmology/cataract-surgery/news/print/ocularsurgery-news/\%7B6b9588ce-f9ef-48ed-af46-e5ce25aa9ca9\%7D/ same-day-bilateral-cataract-surgery-gains-ground-but-obstacles-remain. Accessed December 20, 2017

50 Schachat AP. Simultaneous bilateral endophthalmitis after immediate sequential bilateral cataract surgery: what's the risk of functional blindness? Am J Ophthalmol 2014;158(02):410-411

51 Bethke W. Is bilateral, same-day cataract the future? Review of Ophthalmology. 2015. Available at: https://www.reviewofophthalmology.com/article/is-bilateral-sameday-cataract-the-future. Accessed December 20, 2017

52 Krader C. Risk analysis finds good safety for bilateral, same-day cataract surgery. Ophthalmology Times. 2015. Available at: http:// ophthalmologytimes.modernmedicine.com/ophthalmologytimes/ news/risk-analysis-finds-good-safety-bilateral-same-day-cataractsurgery?page=0,1. Accessed December 20, 2017 